\title{
ECOSSOCIALISMO: o que é, por que precisamos dele, como chegar lá*
}

\author{
ECOSOCIALISMO: que es, por que lo necesitamos, como llegar
}

\section{ECOSOCIALISM: what is it, why do we need it, how to get there}

DOI: http://doi.org/10.9771/gmed.v13i2.45816

\begin{abstract}
Michael Löwy ${ }^{1}$
Resumo: O ecossocialismo busca fornecer uma alternativa civilizatória radical, fundada nos argumentos básicos do movimento ecológico e na crítica marxista da economia política. Ele opõe, ao progresso destrutivo capitalista, que está levando o mundo a uma catástrofe ecológica sem precedente, uma política fundada em critérios não-mercantis: as necessidades sociais e o equilíbrio ecológico. O ecosocialismo é, ao mesmo tempo, uma estratégia política anticapitalista, que busca a convergência das lutas sociais e ecológicas.
\end{abstract}

Palavras-chave: Capitalismo. Destruição. Natureza. Ecologia. Socialismo.

Resumen: El ecosocialismo busca proporcionar una alternativa civilizadora radical basada en los argumentos básicos del movimiento ecológico y la crítica marxista de la economía política. Se opone, al progreso destructivo capitalista, que está llevando al mundo a una catástrofe ecológica sin precedentes, una política basada en criterios no comerciales: necesidades sociales y equilibrio ecológico. El ecosocialismo es, al mismo tiempo, una estrategia política anticapitalista, que busca la convergencia de las luchas sociales y ecológicas.

Palabras clave: Capitalismo. Ruina. Naturaleza. Ecología. Socialismo.

Abstract: Ecosocialism seeks to provide a radical civilizing alternative based on the basic arguments of the ecological movement and the Marxist critique of political economy. It opposes the capitalist destructive progress, which is taking the world to an ecological catastrophe, a policy based on non-commercial criteria: social needs and ecological balance. Ecosocialism is, at the same time, an anti-capitalist political strategy, which seeks the convergence of social and ecological struggles.

Keywords: Capitalism. Destruction. Nature. Ecology. Socialism.

\section{Uma introdução ao tema}

A civilização capitalista/industrial, baseada na expansão e na acumulação ilimitada de capital, na "mercantilização [commodification] de tudo" (Immanuel Wallerstein), na exploração desumana do trabalho e da natureza, no individualismo e na competição brutais, na massiva destruição do meio ambiente, está em crise. A ameaça crescente de ruptura do equilíbrio ecológico aponta para um cenário catastrófico - o aquecimento global - que coloca em perigo a própria sobrevivência da espécie humana. Estamos diante de uma crise civilizatória que requer uma mudança radical, isto é, uma Grande Transição. 
O ecossocialismo busca fornecer uma alternativa civilizatória radical, fundada nos argumentos básicos do movimento ecológico e na crítica marxista da economia política. Ele opõe, ao progresso destrutivo (Marx) capitalista, uma política fundada em critérios não-monetários: as necessidades sociais e o equilíbrio ecológico. Trata-se, ao mesmo tempo, da crítica da "ecologia de mercado", que não põe em questão o sistema capitalista, e do "socialismo produtivista", que ignora a questão dos limites naturais. O planejamento ecológico democrático, onde as principais decisões são tomadas pela própria população - e não pelo "mercado" ou por um Politburo -, é uma das dimensões-chave do ecossocialismo.

$\mathrm{Na}$ Grande Transição a esse novo modo de vida, a esse novo modo de produção e de consumo, setores inteiros do sistema produtivo devem ser suprimidos - começando pelos combustíveis fósseis responsáveis pela mudança climática - ou reestruturados, e novos setores devem ser desenvolvidos sob a premissa necessária do pleno emprego da totalidade da força de trabalho, em condições iguais de trabalho e salários. Essa premissa é essencial, não apenas por ser um requisito de justiça social, mas também para assegurar o engajamento dos trabalhadores no processo de transformação estrutural das forças produtivas. Esse processo é impossível sem o controle público dos meios de produção e sem planejamento, isto é, decisões públicas quanto a investimento e mudança tecnológica, que devem ser retiradas dos bancos e das empresas capitalistas para que sirvam ao bem comum da sociedade.

A própria sociedade, e não uma pequena oligarquia de proprietários - nem uma elite de tecnocratas -, deve poder escolher, democraticamente, que linhas da produção serão privilegiadas, e quanto recurso será investido em educação, saúde ou cultura. Os preços dos bens não devem ser deixados às "leis da oferta e da demanda", mas, até certo ponto, determinados de acordo com escolhas sociais e políticas, como também segundo critérios ecológicos, levando à taxação de certos produtos e a preços subsidiados de outros. Longe de ser "despótico", o planejamento é o exercício, pela sociedade inteira, de sua liberdade: liberdade de decisão e libertação das "leis econômicas" alienadas e reificadas do sistema capitalista, que vêm determinando as vidas e mortes dos indivíduos, aprisionando-os em uma "jaula de aço" (Max Weber) econômica. O planejamento e a redução do tempo de trabalho são os dois passos decisivos da humanidade em direção àquilo que Marx chamou de "reino da liberdade". Um incremento significativo do tempo livre é, ademais, condição para a participação democrática do povo trabalhador na discussão e na administração da economia e da sociedade.

A concepção ecossocialista de planejamento é nada mais do que a democratização radical da economia: se decisões políticas não devem ser deixadas a uma pequena elite de governantes, por que o mesmo princípio não deveria se aplicar também às decisões econômicas? Enquanto no capitalismo o valor de uso é apenas um meio a serviço do valor de troca e do lucro - o que, aliás, explica por que tantos produtos na sociedade contemporânea são substancialmente inúteis ou produzidos com obsolescência programada -, em uma economia ecossocialista planejada o valor de uso é o único critério para a produção de bens e serviços, com consequências de grande alcance econômico, social e ecológico (KOVEL, 2002). 
Em uma produção democraticamente organizada, o plano diz respeito às principais opções econômicas, e não à administração de restaurantes locais, armazéns e padarias, pequenas lojas, empresas artesanais ou serviços. É importante enfatizar que o planejamento não é contraditório com a autogestão, por parte dos trabalhadores, de suas unidades produtivas. Enquanto a decisão de transformar uma fábrica de automóveis em uma unidade de produção de ônibus e veículos sobre trilhos é tomada pela sociedade como um todo, através do plano, a organização interna e o funcionamento daquele estabelecimento industrial devem ser objeto da gestão democrática por parte de seus próprios trabalhadores. Já houve muita discussão sobre o caráter "centralizado" ou "descentralizado" do planejamento, mas podemos argumentar que a verdadeira questão é o controle democrático do plano, em todos os seus níveis, local, regional, nacional, continental, e, esperamos, internacional: assuntos ecológicos como o aquecimento global são planetários, e só podem ser enfrentados em escala global. Pode-se chamar essa proposta de planejamento global democrático: ele é o oposto do que tem sido usualmente descrito como "planejamento centralizado", uma vez que as decisões econômicas e sociais não são tomadas por qualquer "centro", mas sim, democraticamente, pelas populações envolvidas.

O planejamento ecossocialista é, portanto, fundado sobre um debate democrático e pluralista, em todos os níveis de tomada de decisões: propostas diferentes são submetidas à população interessada, sob forma de partidos, plataformas ou outros movimentos políticos, e delegados são eleitos. Entretanto, a democracia representativa deve ser completada - e corrigida - pela democracia direta, na qual as pessoas escolhem diretamente, nos níveis local, nacional, e, posteriormente, global, entre grandes opções sociais e ecológicas. O transporte público deve ser gratuito? Os proprietários de carros privados devem pagar impostos especiais para financiar o transporte público? A energia solar deve ser subsidiada, de modo a competir com a energia fóssil? A carga semanal de trabalho deve ser reduzida a 30, 25, ou menos, horas, mesmo se isso significar uma redução da produção? A natureza democrática do planejamento não é contraditória com a existência de especialistas, mas o papel deles não é decidir, e sim apresentar seus pontos de vista - muitas vezes diferentes, quando não contraditórios - à população, deixando que ela escolha a melhor solução.

O que garante que o povo fará as escolhas ecológicas corretas, mesmo ao preço de abrir mão de alguns de seus hábitos de consumo? Não há tal "garantia", o que há é a aposta na racionalidade das decisões democráticas uma vez que o poder do fetichismo da mercadoria tenha sido quebrado. É claro que erros serão cometidos pelas escolhas populares, mas quem acredita que os especialistas também não cometem erros? Não se pode imaginar o estabelecimento de uma tal nova sociedade sem que a maioria da população tenha atingido, por sua própria luta, por sua autoeducação, por sua experiência social, um alto nível de consciência socialista/ecológica, e isso torna razoável supor que erros, incluindo decisões que sejam inconsistentes com as necessidades ambientais, serão corrigidos. De todo modo, não seriam as alternativas propostas - o mercado cego, uma ditadura ecológica de "especialistas" - muito mais perigosas do que o processo democrático, com todas as suas contradições? 
A Grande Transição do progresso destrutivo capitalista para o ecossocialismo é um processo histórico, uma transformação revolucionária permanente da sociedade, da cultura, das mentalidades. Essa transição não deve levar apenas a um novo modo de produção e a uma sociedade igualitária e democrática, mas também a um modo de vida alternativo, uma nova civilização ecossocialista, para além do reinado do dinheiro, dos hábitos de consumo artificialmente produzidos pela propaganda, da produção ilimitada de mercadorias inúteis e/ou nocivas ao meio ambiente. É importante enfatizar que um processo de tal magnitude não pode começar sem uma transformação revolucionária das estruturas sociais e políticas, tampouco sem o suporte ativo a um programa ecossocialista pela ampla maioria da população. $\mathrm{O}$ desenvolvimento da consciência socialista e da percepção ecológica é um processo para o qual o fator decisivo é a apropriação, por parte dos povos, de experiências coletivas de luta, de confrontações locais e parciais rumo à mudança radical da sociedade.

Deveria o desenvolvimento ser uma meta, ou a escolha deveria recair sobre o "crescimento negativo" [décroissance]? Parece-me que essas duas opções padecem de uma mesma concepção puramente quantitativa do "crescimento", positivo ou negativo, ou, dito de outro modo, do desenvolvimento das forças produtivas. Mas há uma terceira posição, que considero mais apropriada: uma transformação qualitativa do desenvolvimento. Isso significa colocar um ponto final no monstruoso desperdício de recursos pelo capitalismo, baseado na produção, em larga escala, de produtos inúteis e/ou nocivos. A indústria de armamentos é um bom exemplo, mas grande parte dos "bens" produzidos sob o capitalismo, com sua obsolescência programada, não têm outra utilidade que a de gerar lucros para as grandes corporações. O problema não é o "consumo excessivo" em abstrato, mas o tipo de consumo prevalecente, baseado na apropriação conspícua, no desperdício massivo, na alienação mercantil, na acumulação obsessiva, na aquisição compulsiva de pseudo-novidades impostas pela "moda". Uma nova sociedade deve orientar a produção no sentido da satisfação de necessidades autênticas, começando por aquelas que poderiam ser descritas como "bíblicas" - água, comida, vestuário, habitação - mas incluindo também os serviços básicos: saúde, educação, transporte, cultura.

Obviamente, os países do Sul, nos quais essas necessidades estão muito longe de ser satisfeitas, precisarão de um nível muito mais alto de "desenvolvimento" - construção de ferrovias, hospitais, sistemas de saneamento e outras infraestruturas - do que os países industrialmente avançados. Mas não há razão pela qual esse objetivo não possa ser atingido nos marcos de um sistema amigável ao meio ambiente e baseado em energias renováveis. Há países que precisarão produzir grandes quantidades de comida para alimentar populações famintas, mas isso pode e deve ser atingido através de uma agricultura orgânica baseada em unidades familiares, cooperativas ou fazendas coletivistas, como aliás vem sendo argumentado há anos pelos movimentos camponeses internacionalmente organizados em torno da Via Campesina, ao invés dos métodos destrutivos e antissociais do agronegócio industrializado, baseados no uso intensivo de pesticidas, produtos químicos e organismos geneticamente modificados (OGM). Ao invés do atual sistema da dívida, monstruoso, e da exploração imperialista dos recursos do Sul pelos países 
capitalistas/industriais, deve haver um fluxo de ajuda econômica e técnica do Norte para o Sul, sem a necessidade - na qual insistem alguns ecologistas puritanos e ascéticos - de que a população da Europa ou dos EUA "reduzam seu padrão de vida": basta que eles se livrem do consumo obsessivo induzido pelo sistema capitalista, das mercadorias inúteis que não correspondem a qualquer necessidade real.

Como distinguir as necessidades autênticas das artificiais, falsas? As últimas são induzidas pela manipulação mental, isto é, propaganda comercial. O sistema de anúncios invadiu todas as esferas da vida humana nas sociedades capitalistas modernas: suas regras moldam não apenas nutrição e vestuário, mas esportes, cultura, religião e política. Ele invadiu nossas ruas, caixas de correio, telas de TV, jornais, paisagens, de modo permanente, insidioso e agressivo, contribuindo decisivamente para hábitos de consumo conspícuo e compulsivo. Mas há mais: gastam-se quantidades astronômicas de tempo de trabalho, petróleo, eletricidade, papel, produtos químicos e outras matérias primas, todas pagas pelos consumidores, em um ramo da "produção" que não é apenas inútil de um ponto de vista humano, mas que também está em contradição direta com as reais necessidades sociais. A propaganda comercial, dimensão indispensável da economia de mercado capitalista, não teria nenhum lugar em uma sociedade em transição para o ecossocialismo, na qual seria substituída por informações sobre os bens e serviços, proporcionadas pelas associações de consumidores. O critério para distinguir uma necessidade autêntica de uma artificial é sua persistência após a supressão dos anúncios (Coca Cola!). É claro que, durante alguns anos, velhos hábitos de consumo persistirão, e ninguém tem o direito de dizer às pessoas quais são suas necessidades. A mudança nos padrões de consumo é um processo histórico, e também um desafio educacional.

O ecossocialismo é baseado em uma aposta, que já encontramos em Marx: a predominância, em uma sociedade sem classes e liberada da alienação capitalista, do "ser" sobre o "ter", isto é, do tempo livre para o aperfeiçoamento pessoal através de atividades culturais, esportivas, lúdicas, científicas, eróticas e políticas, ao invés do desejo pela posse infinita de bens. A aquisição compulsiva é induzida pelo fetichismo da mercadoria inerente ao sistema capitalista, pela ideologia dominante e pela propaganda comercial: nada prova que ela seja parte de uma "natureza humana eterna", como quer fazer crer o discurso reacionário. Como enfatizou Ernest Mandel (1992, p.206):

\begin{abstract}
A acumulação contínua de mais e mais bens (com 'utilidade marginal' declinante) não é, de modo algum, uma característica universal, e nem mesmo predominante, do comportamento humano. O desenvolvimento de talentos e inclinações a partir de seu próprio interesse; a proteção da saúde e da vida; o cuidado com as crianças; o desenvolvimento de ricas relações sociais [...], tudo isso constitui as grandes motivações, uma vez que as necessidades materiais básicas tenham sido satisfeitas.
\end{abstract}

Isso não significa que não haverá conflitos, particularmente ao longo do processo de transição, entre as exigências de proteção do meio ambiente e as necessidades sociais, entre os imperativos ecológicos e a necessidade de desenvolvimento de infraestruturas básicas, particularmente nos países pobres, entre hábitos de consumo populares e a escassez de recursos. Uma sociedade sem classes não é 
uma sociedade sem contradições nem conflitos! Eles são inevitáveis: será tarefa do planejamento democrático resolvê-los através da discussão pluralista e aberta que conduza à tomada de decisão por parte da própria sociedade a partir de uma perspectiva ecossocialista, liberada dos imperativos do capital e do lucro. Tal democracia de base e participativa é o único caminho para, mais que evitar os erros, permitir sua autocorreção por parte da coletividade social.

\section{Breve panorama da história intelectual do ecossocialismo}

Marx e Engels, que desenvolveram uma compreensão profunda e acurada de questões ecológicas a partir de uma perspectiva socialista, podem ser considerados os precursores do ecossocialismo. É verdade que essas questões não ocupam um lugar central em seu dispositivo teórico, mas isso simplesmente reflete o fato de que, no século XIX, a crise ecológica estava apenas começando, estava longe de ter se tornado tão catastrófica quanto em nossos dias. Ainda assim, pode-se encontrar em seus escritos um conjunto de argumentos e conceitos que são essenciais para a compreensão da conexão entre capitalismo e destruição do meio ambiente, e também para definir uma alternativa ecológica e socialista ao sistema atualmente prevalecente.

É verdade que, em certos escritos de Marx e Engels, e ainda mais nas correntes marxistas dominantes que os sucederam, pode-se encontrar uma abordagem insuficientemente crítica das forças produtivas criadas pelo capital, assim como uma tendência a enxergar no "desenvolvimento das forças produtivas" o fator principal do progresso humano. Entretanto, Marx era um oponente radical do produtivismo, da lógica capitalista da produção pela produção, da acumulação de capital, riqueza e mercadorias como fim em si. A ideia fundamental de uma economia socialista - em contraste com suas caricaturas burocráticas ao longo do século XX - é a da produção de valores de uso, bens que são necessários para a satisfação de necessidades humanas. Além disso, a importância central do progresso técnico para Marx não residia no crescimento infinito de produtos ("ter"), mas na redução da jornada de trabalho e no incremento do tempo livre ("ser") (MARX, 1968b, p.828)2. Como argutamente mostrou Paul Burkett, a ênfase de Marx no autodesenvolvimento comunista, no tempo livre para atividades artísticas, eróticas, intelectuais, em contraste com a obsessão capitalista por mais e mais bens materiais, conduz à redução decisiva da pressão da produção sobre o meio ambiente natural (BURKETT', 2009, p. 329).

Uma importante contribuição marxiana ao pensamento socialista e ecológico é o argumento de que o capitalismo é responsável por uma ruptura metabólica entre as sociedades humanas e o meio ambiente natural. Essa questão é discutida em uma passagem bem conhecida do Livro I de O capital (dentre outras): a conclusão do capítulo sobre a grande indústria e a agricultura. Trata-se de um dos escritos mais importantes de Marx, porque é marcado por uma visão dialética das contradições do "progresso" e de suas consequências destrutivas, sob domínio capitalista, para a natureza:

O modo de produção capitalista [...] desvirtua o metabolismo [Stoffwechsel] entre o homem e a terra, isto é, o retorno ao solo daqueles elementos que lhe são constitutivos

Germinal: marxismo e educação em debate, Salvador, v.13, n.2, p. 471-482, ago. 2021. ISSN: 2175-5604 
e foram consumidos pelo homem sob forma de alimentos e vestimentas, retorno que é a eterna condição natural da fertilidade permanente do solo. [...] E todo progresso da agricultura capitalista é um progresso na arte de saquear não só o trabalhador, mas também o solo, pois cada progresso alcançado no aumento da fertilidade do solo por certo período é ao mesmo tempo um progresso no esgotamento das fontes duradouras dessa fertilidade. Quanto mais um país, como os Estados Unidos da América do Norte, tem na grande indústria o ponto de partida de seu desenvolvimento, tanto mais rápido se mostra esse processo de destruição. Por isso, a produção capitalista só desenvolve a técnica e a combinação do processo de produção social na medida em que solapa [untergräbt] os mananciais de toda a riqueza: a terra e o trabalhador. (MARX, 1968a, p.637-8). ${ }^{3}$

Alguns elementos significativos nessa importante passagem são:

(1) A ideia de que o progresso pode ser destrutivo, um "progresso" na degradação e deterioração do meio ambiente natural. O exemplo escolhido por Marx é limitado - a perda de fertilidade do solo - mas leva-o a levantar a questão mais ampla dos ataques à natureza e às "condições naturais eternas" pela produção capitalista.

(2) A exploração e o empobrecimento dos trabalhadores e da natureza são apresentados desde um ponto de vista similar, como resultado de uma mesma lógica predatória, a lógica da grande indústria capitalista e da agricultura industrial.

Os ecossocialistas modernos são inspirados pelas descobertas de Marx e por sua crítica do capitalismo, mas a questão ecológica ocupa um lugar muito mais central em sua reflexão e em sua ação. $\mathrm{O}$ socialismo ecológico começou a se desenvolver durante os anos 1970 na Europa e nos EUA. Dentre seus pioneiros encontramos Manuel Sacristán (Espanha), Raymond Williams (Inglaterra), André Gorz e JeanPaul Déléage (França), assim como Barry Commoner (Estados Unidos). Durante os anos 1980, James O’Connor descobriu a Segunda Contradição do Capitalismo, entre as forças e as condições da produção. O’Connor fundou o periódico Capitalismo, natureza e socialismo [Capitalism, nature and socialism], que viria a ser posteriormente dirigido por Joel Kovel, autor de influentes ensaios ecológicos anticapitalistas. Uma nova geração de eco-marxistas apareceu nos anos 2000, com John Bellamy Foster e o periódico Monthly Review, enfatizando o conceito marxiano de ruptura metabólica entre as sociedades humanas e o meio ambiente.

Joel Kovel, Ian Angus e outros escreveram em 2008 o Manifesto Ecossocialista de Belém, que foi assinado por centenas de pessoas de mais de 40 países, e distribuído no Fórum Social Mundial em $2009{ }^{4}$. Seguem algumas passagens do documento, que se tornou uma importante referência para ecossocialistas ao redor do mundo:

O movimento ecossocialista tem por objetivos parar e reverter o desastroso processo de aquecimento global em particular, e o ecocídio capitalista em geral, e construir uma alternativa prática radical ao sistema capitalista. O ecossocialismo é fundado em uma economia transformada, estabelecida sobre os valores não-monetários da justiça social e do equilíbrio ecológico. [...] Ele redefine o caminho e o objetivo do socialismo a partir de uma moldura ecológica e democrática.

O ecossocialismo envolve uma transformação social revolucionária que implicará na limitação do crescimento e na transformação das necessidades através de um profundo deslocamento dos critérios econômicos, de quantitativos a qualitativos, enfatizando o valor de uso ao invés do valor de troca. 
Esses objetivos requerem tanto a tomada democrática de decisões na esfera econômica, habilitando a sociedade a definir coletivamente seus objetivos de investimento e de produção, quanto a coletivização dos meios de produção. Só o caráter coletivo da tomada de decisões e da propriedade da produção podem oferecer a perspectiva de longo prazo que é necessária para o equilíbrio e a sustentabilidade de nossos sistemas social e natural.

A rejeição do produtivismo e o afastamento dos critérios econômicos quantitativos em direção aos qualitativos envolve repensar a natureza e os objetivos da produção e da atividade econômica em geral. Atividades humanas criativas, não produtivas e reprodutivas essenciais, como o trabalho doméstico, a criação das crianças, o cuidado, a educação de jovens e adultos, as artes, serão valores centrais em uma economia ecossocialista.

\section{Por que os ambientalistas devem ser socialistas}

O sistema capitalista, completamente baseado, desde a Revolução Industrial, em combustíveis fósseis, é o responsável pela crise ecológica atual, e, em particular, pela mudança climática. Sua lógica irracional de expansão e acumulação infinitas, desperdício de recursos, consumo ostentatório, obsolescência programada, produtivismo obcecado com a busca do lucro a qualquer preço, está levando o planeta à beira do abismo.

Poderia um "capitalismo verde" ser uma solução? A falha de todas as conferências internacionais em efetivamente lidar com o problema da mudança climática é a demonstração mais óbvia de que as forças políticas comprometidas com a "economia de mercado" capitalista não podem prevenir a catástrofe vindoura. Para os setores mais obscurantistas da oligarquia fóssil - presentemente governando o mais poderoso país capitalista/industrial do mundo - a mudança climática é uma "farsa". Essa posição absurda não é compartilhada pela maior parte dos outros governos, que se encontraram em Paris em 2015 e chegaram a uma resolução comum: devem ser feitos sérios esforços para manter o aumento de temperatura abaixo dos $2^{\circ} \mathrm{C}$, ou mesmo $1,5^{\circ} \mathrm{C}$, para que seja possível evitar consequências dramáticas. Todos os 195 governos concordaram com medidas voluntárias de redução de suas emissões de $\mathrm{CO}_{2}$. Infelizmente, não é muito provável que esses governos cumpram sua palavra, uma vez que não há medidas de controle estabelecidas, nem, muito menos, sanções para o não cumprimento. Mesmo no caso em que todos os governos mantivessem suas promessas (incluindo, é claro, o dos EUA), cientistas calcularam que a temperatura deve subir pelo menos 3 , ou mesmo 4 graus. Isso significa o desenvolvimento de um processo irreversível de mudança climática, com resultados extremos para a humanidade.

A conclusão óbvia é que uma racionalidade limitada pelo mercado capitalista, com seu míope cálculo de perdas e ganhos, não pode romper a dependência histórica dos combustíveis fósseis e está em intrínseca contradição com a racionalidade ecológica, que leva em conta os ciclos naturais. Não se trata de opor capitalistas ecocidas "malvados" a capitalistas verdes "bonzinhos"; o destruidor do equilibrio da natureza é o próprio sistema, baseado na competição insensível e na corrida pelo lucro rápido. 
Contra o fetichismo da mercadoria e a autonomização reificada da economia causados pelo capitalismo, o desafio do futuro é o desenvolvimento de uma "economia moral", no sentido usado por E.P. Thompson, ou seja, a política econômica deve ser fundada em critérios não-monetários e extraeconômicos, sociais e ecológicos, democraticamente decididos pela população. Reformas parciais são insuficientes; o que é necessário é substituir a micro-racionalidade do lucro por uma macro-racionalidade social e ecológica, que demanda uma redução do consumo energético, a rápida substituição das energias fósseis pelas limpas, a superação do consumismo. Em uma palavra, uma mudança de civilização. Esse processo é impossível sem o controle público sobre os meios de produção e o planejamento, isto é, decisões públicas sobre investimento e mudança tecnológica, que devem ser tiradas dos bancos e das empresas capitalistas de modo a servir ao bem comum da sociedade. Uma ecologia que respeite as regras da "economia de mercado" é incapaz de enfrentar o desafio. Alternativas radicais são necessárias, e, uma vez que a raiz do problema é sistêmica, a ecologia tem de se tornar antissistêmica, isto é, ecossocialista.

Os ecologistas que imaginam estar à altura da tarefa sem a crítica marxiana do capitalismo e sem uma alternativa radical, pós-capitalista, estão errados. Uma ecologia que não reconheça a relação entre "produtivismo" e a lógica do lucro está fadada ao fracasso - ou pior, à absorção pelo sistema. Há muitos exemplos. A falta de uma postura anticapitalista coerente levou a maior parte dos Partidos Verdes europeus - notadamente na França, na Alemanha, na Itália, na Bélgica - a se tornarem meros parceiros “eco-reformistas" da administração social-liberal do capitalismo por governos de centro-esquerda.

Alguns Verdes argumentam que a natureza não se saiu muito melhor no socialismo do que no capitalismo. Há um fundo de verdade nesse argumento, e é por isso mesmo que o ecossocialismo tem um programa muito diferente daquele do assim chamado "socialismo realmente existente" (um conceito bastante duvidoso) do passado.

\section{Por que os socialistas devem ser ambientalistas}

No século XXI, a crise ecológica, e, especialmente, a mudança climática, se tornou uma questão social e política decisiva. Está em jogo a própria sobrevivência da vida no planeta Terra. Uma teoria ou um movimento socialista que não integrem a ecologia como elemento central em seu programa e em sua estratégia serão anacrônicos e irrelevantes.

A crise ecológica planetária, que é uma crise de civilização, tem sua mais ameaçadora expressão no fenômeno do aquecimento global. Resultado da acumulação de gases de efeito estufa, sobretudo o dióxido de carbono, lançados na atmosfera pela queima de combustíveis fósseis, como petróleo e carvão, o processo de mudança climática é um desafio sem precedentes na história da humanidade. Mas o que acontecerá se a temperatura do planeta subir além dos $2^{\circ} \mathrm{C}$ ? Os riscos são conhecidos graças aos trabalhos do IPCC, o Painel Intergovernamental sobre Mudanças Climáticas [Intergovernmental Panel on Climate Change]. Elevação do nível dos mares, com o risco de submersão de boa parte das cidades marítimas 
erigidas pela civilização humana, de Daca em Bangladesh a Amsterdã, Veneza ou Nova Iorque. Desertificação em escala gigantesca: o deserto do Saara poderia chegar até Roma. Falta de água potável. Catástrofes "naturais", como furacões, inundações etc., com frequência e intensidade crescentes. Poderíamos continuar a lista. A que temperatura $\left(5,6\right.$ ou $\left.7^{\circ} \mathrm{C}\right)$ o planeta deixaria de ser habitável por nossa espécie? Infelizmente, no momento não dispomos de um planeta de reposição no universo existente conhecido pelos astrônomos...

Extremamente preocupante é o fato de que o processo de aquecimento global vem ocorrendo a uma velocidade muito maior do que a prevista. O acúmulo de dióxido de carbono, a subida da temperatura, o derretimento dos gelos polares e da "neve eterna" das montanhas, as secas, as inundações: tudo isso está acontecendo muito rápido, de modo que os relatórios e balanços realizados pelos cientistas já parecem muito otimistas assim que a tinta em que foram impressos acaba de secar. Já não se fala mais do que acontecerá em 2100, mas daquilo que nos aguarda nos próximos 10, 20, 30 anos.

A teoria e a prática socialistas precisam levar em conta a crise ecológica e o aquecimento global como uma questão decisiva para a humanidade, questão essa que se tornará mais e mais importante ao longo do século XXI. Ignorar isso, ou tratar o problema como "secundário", condenará o socialismo à irrelevância. Alguns socialistas admitem a importância de incorporar a ecologia, mas objetam que o termo "ecossocialismo" seria redundante, uma vez que o socialismo já inclui ecologia, feminismo, antirracismo etc. Entretanto, a palavra ecossocialismo carrega um forte significado político, apontando para importantes mudanças na reflexão socialista:

(1) um novo entendimento do capitalismo, como sistema baseado não apenas na exploração, mas também na destruição - a destruição massiva das condições de vida no planeta;

(2) uma nova compreensão do socialismo não apenas como mudança nas formas de propriedade, mas como uma transformação civilizatória, incluindo o aparato produtivo, os padrões de consumo, o modo de vida em sua totalidade;

(3) uma visão crítica das experiências do século XX em nome do socialismo.

O socialismo do século XX, em suas tendências dominantes (socialdemocracia e comunismo de tipo soviético), ignorou o meio ambiente e adotou, sem hesitação, o aparato produtivo do Ocidente (capitalista), com consequências muito negativas. A experiência da União Soviética ilustra os problemas que resultam de uma apropriação coletiva do aparato produtivo capitalista. É verdade que durante os primeiros anos após a Revolução de Outubro uma corrente ecológica pôde se desenvolver, e certas medidas de proteção foram tomadas pelas autoridades soviéticas. Entretanto, com o processo de burocratização stalinista, as tendências produtivistas, tanto na indústria quanto na agricultura, foram impostas através de métodos totalitários, enquanto os ecologistas foram marginalizados e eliminados. A catástrofe de Chernobyl é um exemplo extremo das consequências desastrosas da imitação das tecnologias produtivas ocidentais. Uma mudança nas formas de propriedade que não seja seguida pela administração democrática e pela reorganização do sistema produtivo só pode levar a um beco sem saída. 
Como tornar realidade a visão ecossocialista; o papel do ecossocialismo na ampla convergência de movimentos por uma Grande Transição

Referências: Sonhar e lutar por um socialismo verde, ou, de acordo com alguns, um comunismo solar, não significa que não devamos batalhar por reformas concretas e urgentes. Sem quaisquer ilusões em um "capitalismo limpo", deve-se buscar ganhar tempo e impor, aos poderes instituídos, mudanças elementares, começando por uma drástica redução na emissão de gases do efeito estufa. Barrar um gigantesco oleoduto, uma mina de ouro poluente, uma usina alimentada a carvão, tudo isso é parte do movimento mais amplo de resistência chamado Blockadia por Naomi Klein. Igualmente significativas são experiências locais de agricultura orgânica, energia solar cooperativa, gestão comunitária de recursos.

Essas lutas em torno de questões concretas são importantes, não apenas porque vitórias parciais são bem-vindas, mas também porque elas contribuem para a elevação do nível de consciência ecológica e socialista, e porque promovem atividade e auto-organização desde baixo, constituindo pré-condições decisivas e necessárias para uma transformação radical do mundo, isto é, para uma Grande Transição a uma nova sociedade e um novo modo de vida.

Essas questões, e outras similares, estão no coração da agenda do "movimento de movimentos", o Movimento por Justiça Global [Global Justice Movement] e os Fóruns Sociais Mundiais, desenvolvimentos decisivos que vêm permitindo, desde 1999, a convergência de movimentos sociais e ambientais em uma luta comum contra o sistema.

O ecossocialismo é apenas uma das componentes do "movimento de movimentos": ele não pretende ser "mais importante" ou "mais revolucionário" que os outros, no que seria uma competição inútil, nem também um guarda-chuva comum para todos. Sua ambição é ser parte do ethos comum dos vários movimentos que almejam uma Grande Transição. Como muitos movimentos sociais, e o próprio Fórum Social Mundial, o ecossocialismo se enxerga como um movimento internacional: uma vez que a catástrofe ecológica é global e não conhece fronteiras, a luta contra ela também deve ser globalizada. Já houve diversas tentativas de criar uma Rede Ecossocialista Internacional, ou uma Internacional Ecossocialista, mas seu sucesso tem sido, até o momento, limitado.

Há diversas interseções importantes entre o ecossocialismo e outros movimentos sociais. Por exemplo, algumas líderes eco-feministas (como Ariel Salleh e Terisa Turner) também são ecossocialistas, e vice-versa: elas enxergam ambas as propostas como convergentes e complementares. No Movimento de Justiça Climática [Climate Justice Movement], antirracismo e ecossocialismo caminham juntos na luta contra a destruição capitalista das condições de vida de comunidades discriminadas racialmente. Outra interseção significativa diz respeito aos movimentos indígenas: muitos líderes indígenas são ecossocialistas, e o ecossocialismo vê o modo de vida indígena, enraizado na solidariedade comunitária e no respeito à Mãe 
Natureza, como uma inspiração para sua própria perspectiva. Outros exemplos podem ser dados: convergência com movimentos camponeses, com sindicatos de trabalhadores, com comunidades cristãs de base etc. Há também iniciativas comuns com outros movimentos ecológicos radicais, isto é, antissistêmicos, como a ecologia social (inspirada por Murray Bookchin), o decrescimento [de-growth] e outros Verdes de Esquerda.

O movimento de movimentos acredita que o Sistema tem de ser transformado, e que outro mundo é possível para além da mercantilização [commodification], da destruição do meio ambiente, da exploração e da opressão. Os ecossocialistas esperam que sua proposta se torne um dos componentes decisivos da Grande Transição rumo a esse Novo Mundo possível. As arraigadas elites dominantes do sistema são incrivelmente poderosas, e as forças da oposição radical ainda são pequenas. Mas essas forças são a única esperança de que o curso catastrófico do "crescimento" capitalista possa ser freado. Walter Benjamin definiu as revoluções não como a locomotiva da história, como Marx acreditava, mas sim como a possibilidade de a humanidade puxar os freios de emergência do trem, antes que ele despenque no abismo.

BURKETT, Paul. Ecological economics. Toward a red and green political economy. Chicago: Haymarket Books, 2009.

KOVEL, Joel. Enemy of nature, the end of capitalism or the end of the world? Nova Iorque: Zed Books, 2002.

MANDEL, Ernest. Power and money. A marxist theory of bureaucracy. London: Verso, 1992, p.206.

MARX, Karl. Das kapital, I. Berlin: Dietz Verlag, 1968a.

MARX, Karl. Das kapital, III, MEW, vol.25. Berlin: Dietz Verlag, 1968b.

\begin{abstract}
Notas
* O tradutor para o português é o professor Victor Neves (UFES).

1 Doutor em Ciências Sociais pela Universidade de Paris-Sorbonne. Diretor emérito de pesquisa do Centre National de la Recherche Scientifique (CNRS). Orcid: https://orcid.org/0000-0001-5679-0927. E-mail: michael.lowy1@gmail.com.

2 A oposição entre "ter" e "ser" é discutida amiúde nos Manuscritos de 1844 [N. do T.: Ed. bras.: MARX, Karl. Manuscritos econômico-filosóficos. São Paulo: Boitempo, [1844] 2004]. Sobre o tempo livre como fundação do "reino da liberdade" socialista, cf. Marx, 1968b, p.828.

3 Karl Marx, O capital, vol.1, p.637-638. Ver MARX, 1968a, p.528-530. [N. do T.: a tradução dessa citação foi tomada emprestada da mais recente edição brasileira de $\mathbf{O}$ capital, deixando no texto, entretanto, as remissões às palavras do original alemão feitas por Löwy. Cf. MARX, Karl. O capital: crítica da economia política. Livro I: o processo de produção do capital. São Paulo: Boitempo, [1867] 2013, p.572-574.]

${ }^{4}$ [N. do T.: Michael Löwy é, ele próprio, um dos autores do Manifesto Ecossocialista de Belém, que tem esse nome devido a seu lançamento no Fórum Social Mundial de 2009 realizado em Belém, capital do Pará, no Brasil.]
\end{abstract}

Recebido em: 24 de agosto de 2021

Aprovado em: 27 de agosto de 2021 